\title{
Multi-criteria for Selection of SmartPhone Brands Product using AHP-TOPSIS Method
}

\author{
Akmaludin \\ STMIK Nusa Mandiri Jakarta \\ Jakarta, Indonesia \\ akmaludin.akm@nusamandiri.ac.id
}

\author{
Muhammad Badrul \\ STMIK Nusa Mandiri Jakarta \\ Jakarta, Indonesia \\ muhammad.mbl@nusamandiri.ac.id
}

\begin{abstract}
Today's communication is very important to do, this can be done by using communication tools that are currently being used by everyone, none other than SmartPhone, so people are competing to get it. Many found difficulties in choosing a SmartPhone Brand Product that suits the wishes of each user from a number of alternatives such as Advance, Xiaomi, OPPO, SAMSUNG, and VIVO, because many criteria must be considered such as memory capacity, battery durability, sharpness of capture camera, the form of design producy, the number of features produced from the product, which is equally important is the overall performance of the product. This difficulty is a general matter discussed by each user, because it requires the best solution that can be used to solve the problem. One method that can be used to select the right SmartPhone is the Analytic Hierarchy Process (AHP) method combined with the TOPSIS method. In this case AHP is used to determine the preference quantity in weighting and TOPSIS is used for mathematical detailed calculations of a number of criteria specified in ranking from a number of alternatives. The results obtained based on the mathematical calculation process are the first rank brand products with the highest weight of 0.597 from SAMSUNG, followed by a weight of 0.586 from OPPO, then weighing 0.555 from Advance, then weighing 0.511 from VIVO, and the smallest weight 0.491 from Xiaomi.
\end{abstract}

Keywords-AHP, BrandProduct, Multi-criteria, TOPSIS.

\section{INTRODUCTION (HEADING 1)}

Seeing the level of human activity in the virtual world at this time, giving an illustration to anyone in the eye to be able to understand the importance of a very high level of communication that cannot be limited by space and time. Technology is able to compensate for the busy conditions of each person to be able to communicate with each other remotely, even know no time. SmartPhone is one of the technologies closest to the current conditions. Once the importance of the tool, so that all interests can be resolved easily. There is a very urgent concern for communication devices in the form of SmartPhone, which is the superiority aspect of each Product Brand which is the most important criterion in the race for the Product Brand selection for SmartPhone. the size of the storage media is memory, the battery strength is always mobile, the sharpness of the camera's capture power in the form of photos and images, the real appearance of the product design, the number of features produced by the product, and most of all the performance of the Brand Product SmartPhone. Brand Products SmartPhone are used as research material, namely Advance, Xiaomi, OPPO, SAMSUNG, and VIVO.

To help users determine their choice of SmartPhone Brand Product that suits their needs, given an optimal solution to become a barometer in obtaining the right SmartPhone Brand Poduct is a Multi-criteria method, the Analytic Hierarchy Process (AHP) will be combined with the TOPSIS method. Both of these methods have different functions in their collaboration. AHP is used in determining preferences from a number of plural criteria, while TOPSIS is used to calculate the detail of the selection process for a number of alternatives. 


\section{LITERATURE REVIEW}

\subsection{Analytic Hierarchy Process (AHP).}

Every human being to carry out a decision making process is expected to be able to increase the level of effectiveness in decision making. To determine the decision problem at the same level, the level of importance and choice of evaluation decisions from the decision criteria can be different assessments. AHP can provide opportunities for effective decision making in solving decision problems such as this condition. mathematical methods that evaluate criteria and alternatives that are qualitative and quantitative by considering the priority of groups or individuals together in decision making [1].

Famous figures such as Saaty had developed AHP in 1977 and he had succeeded in making it used to solve decision-making problems. AHP can be described as multi-criteria decision making and forecasting methods used in the decision hierarchy and provide a percentage distribution of decision points in terms of factors that influence decisions [2]. AHP is based on comparisons used to determine the important values of decision points in terms of factors that influence decisions using a predetermined comparison scale [2]. Saaty realized that in order to succeed in decision problems, accurate mathematics was needed not complex mathematics and he had developed AHP as a result of analysis for complex situations and decision making for complex, simplified problems [3], AHP could be used for alternative determination and criteria. specified from the eigenvector value [4] can also be combined with other methods in a multicriteria cluster such as promethee [5] or using other methods. AHP configures hierarchically and visualizes complex multi-criteria problems so AHP is used effectively in solving problems faced in many scientific fields [6].

To make a decision in an organized way to produce priorities, we need to decipher the decision into the following steps 1) Define the problem and determine the type of knowledge sought; 2) The hierarchical structure of decisions from above with structured decision objectives, then goals from a broad perspective through the middle level (criteria that depend on the elements below) to the lowest level (which is usually a set of alternatives); 3) Create a set of pairwise comparison matrices. Each element at the top level is used to compare elements at the two levels below; 4) Use priorities obtained from comparisons to compare priorities at the level below. Do this for each element to the lowest level as an alternative [2], [6], [7].

\subsection{Technique for Order of Preference by Similarity to Ideal Solution (TOPSIS).}

TOPSIS method is one of the Multi-criteria that gives a description of the rank listed in the dataset, if there is an addition to the dataset it can lead to changes in the next ranking [8], [9]. To handle problems like this can be done by determining the new preference and then adding the next data set, so that TOPSIS can be said to be a mixed method in determining the ranking.

TOPSIS and AHP are part of the Multi-criteria Decision Making (MCDM), usually the nature of Multi-criteria has the same stages. The following is a general description of the main steps in making Multi-criteria decisions as follows: a) Establishing system evaluation criteria that return the system's ability to its objectives; b) Develop alternative systems to achieve goals (produce alternatives); c) Evaluating alternatives in terms of criteria (criteria function values); (d) Applying normative criteria analysis methods; e) Receive one alternative as optimal preference; f) If the final solution is not accepted, collect new information and enter the next iteration of Multi-criteria optimization [10]. The things like this, will be shown in the determination of preferences derived from the eigenvector value, where the determination of the eigenvector will experience five iterations to get an eigenvector with a value without difference. This means that there is not the slightest difference to the decimal value generated from the eigenvector that was obtained last with the previous eigenvector value and so on.

Decision making plays an important role in various life cycles, to identify objectives that are simple Analytic Hierarchy Process (AHP) then used to prioritize preferences. The output of AHP is used as an input for Preference Order Technique by Similarity to Ideal Solutions (TOPSIS) which produces metrics that decide the best alternative among so many alternatives [11], so here it will show that there is good collaboration between AHP and TOPSIS when viewed from the technique use of dataset results.

\subsection{Expert Choice.}

The Expert Choice application is software that can be used to prove the harmony between the results obtained by the determination of the eigenvector which is processed with the algebra matricis method correctly. Algebra matricis can be used as a standard of completion with mathematical concepts through several iterative stages. The iteration process that occurs in the determination of eigenvector values is not always the same, depending on the amount of deviation value 
produced. The greater the deviation value it is possible for an iterative process to determine the eigenvector bias repeatedly, on the contrary if the resulting deviation is small, it allows not too much iteration. The important note for the process must be at least one time, because the determination of the eigenvector difference is obtained from the reduction between the first eigenvector and the second eigenvector. The Expert Choice 2000 was made like making a hierarchy [12] with a different concept, namely by determining the level of objectives, level criteria, and alternative levels that are designed in the same way as hierarchy but the appearance of entries is different.

The appearance of the two dimensions of Expert Choice 2000 can be seen in (Figure 1), where there are seven criteria compared to one another, the value displayed in Expert Choice 2000 is a process that is converted from an arithmetic scale obtained from a number of approximately 140 respondents were changed to a geometric scale and converted to scale AHP scale 1-9. The results obtained are shown as (Figure 2) and are used to determine the weight of each criterion which becomes a ranking benchmark to determine the criteria weights in TOPSIS.

\begin{tabular}{|l|l|r|r|r|r|r|}
\hline & Performance & Feature & \multicolumn{1}{l}{ Design } & \multicolumn{1}{l|}{ Camera } & Battery & \multicolumn{1}{l|}{ Memory } \\
\hline Performance & & 1.401 & 1.877 & 1.451 & 1.41 & 1.35 \\
\hline Feature & & & 1.452 & 1.613 & 1.625 & 1.144 \\
\hline Design & & & & 1.2 & 1.798 & 1.696 \\
\hline Camera & & & & & 1.188 & 1.389 \\
\hline Battery & & & & & & 1.495 \\
\hline Memory & Incon: 0.02 & & & & & \\
\hline
\end{tabular}

Figure 1. Display Input Expert Choice 2000

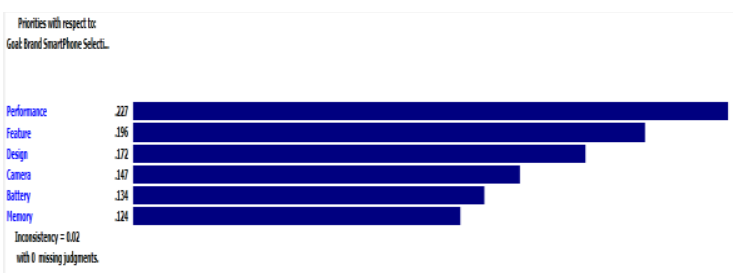

Figure 2. Eigenvector Output Results

\subsection{The calculation process used in TOPSIS.}

To understand more about the combination of AHP and TOPSIS, first learn how to determine the criteria that can be used to measure a SmartPhone Brand Product. Some equations that can be used to determine the eigenvector value and this is the usage limit of AHP as a determinant of the criteria, then the results of the eigenvector are used in the mathematical process using the TOPSIS method. As for a number of equations that can be used as follows: Determining the normalized table, this is done to determine the position of the value of a determinant measured through a scale range obtained from the magnitude of the results of squaring, so that it can determine where the position of a point is, as for the equation used in (equation 1).

$$
\mathrm{R}_{\mathrm{ij}}=\frac{x_{i j}}{\sqrt{\sum_{i=1}^{m} x_{i j}^{2}}}
$$

Thus each criterion determined by its size can be determined by the point where the point is located. Next is to combine the amount of value calculated with AHP in determining the normalization weight, as for the equation used to determine the normalization weight using (equation 2).

$$
y_{i j}=w_{i} r_{i j}
$$

For using the (equation 2) illustrates that the results of each of the normalization processes occur multiplication between the results of normalization of data with the amount of criteria obtained through eigenvector values, thus the amount of results will be processed further.

The next step is to determine the magnitude of the ideal positive solution and the magnitude of the negative ideal solution. This is done by summarizing each criterion to determine the maximum value and minimum value of each criterion used to determine the SmartPhone Brand Product, of course there will be two equations that can be used to determine positive ideal solution and negative ideal solution in (equation 2) and (equation 4). Positive ideal solutions can determine the value of a criterion taken from weighted normalization, which is reduced by the maximum value of each of the squared criteria, as well as the negative ideal solution obtained from the value of each criterion line divided by the lowest value of each criteria taken from weighted normalization, which is reduced by the value of the minimum amount of each of the squared criteria. Then each row can be added to determine the dimension value of $\mathrm{V}$.

$$
\begin{aligned}
& A^{+}=\left(y 1^{+}, y 2^{+}, y 3^{+}, \ldots, y n^{+}\right) \\
& A^{-}=\left(y 1^{-}, y 2^{-}, y 3^{-}, \ldots, y n^{-}\right)
\end{aligned}
$$

Dimension $\mathrm{V}$ is obtained based on a combination of processes from negative ideal solutions divided by the sum of positive ideal solutions and negative ideal solutions. The equation $s$ that can be used can be seen in (equation 5). Thus ranking can be determined from each alternative, which one has the greatest weight is in the top position and which has 
the lowest value is the lowest position and this does not use the index system.

$$
\mathrm{V}=\frac{D i^{-}}{D i^{-}+D i^{+}}, \mathrm{i}=1,2,3, \ldots \mathrm{m}
$$

\section{Proposed Method}

The research method that can be used as a handle in collecting this data is based on several sources, namely the questionnaire method and a number of preferences about the SmartPhone Brand Product as a form of field research and to integrate the two literature studies as a form of unification which is equation in mathematical completion methods prepared starting from determining the value of decisions arranged in a table to simplify the problems that vary. Then determine the criteria and alternatives to be resolved.

The stages of research that will be carried out are 1) Conducting data collection from several methods, namely the questionnaire method, field research, and literature study methods; 2) Process the classification of data to be grouped into their respective criteria; 3) Perform calculations on the eigenvector value carried out using the AHP method; 4) In line with the AHP method, the process of forming data normalization is carried out with the TOPSIS method; 5) Perform a combination process of both AHP and TOPSIS methods, namely determining the weight of normalization; 6) Determine the size of the Positive ideal solution value; 7) In line with that also determines the magnitude of the solution to the negative ideal solution value; 8) Determine the V point process; 9) Determine the ranking of a number of alternatives from the Procurement SmartPhone Brand Product. The stages of this research must be carried out according to the rules of the game that allow each stage to display the results as outlined in a table as an illustration of the understanding of the use of the AHP and TOPSIS methods.

The process of the research stage that requires nine stages of the process can be described simply as can be seen in (Figure 3). This provides interrelated evidence between the AHP method and the TOPSIS method. Where AHP gives priority to each criterion, obtained from the eigenvector value that has been through iterations until there is no difference between the last eigenvector value of the iteration process with the previous eigenvector value. This indicates that the acquisition of eigenvector values gives optimal results without any difference behind the decimal places value. And it can be proven by the Expert Choice 2000 application, which gives the same value as mathematically algebra matrices. This eigenvector value will be used in the mathematical process through the TOPSIS method.

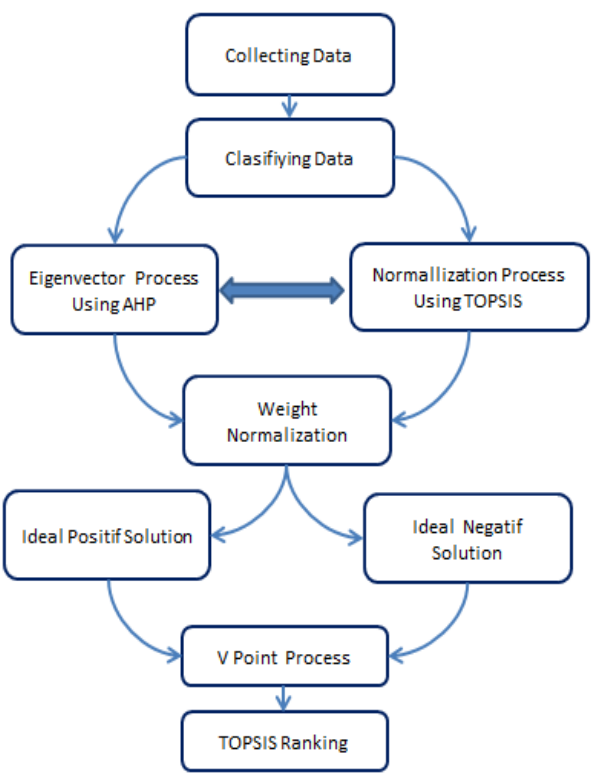

Figure 3. TOPSIS Algoritm

\section{RESULT AND DISCUSSION}

Ranking of a smartphone product brand using the TOPSIS method, has many stages that must be passed, the first step is to determine the value of the decision. The decision value used has seven levels of assessment starting from very bad with a weight of one to very good assessment with a weight of seven, note (Table 1) which describes the point of assessment of the smart phone product brand that was appointed in this study..

Table 1. Point of Branda Product Assessment

\begin{tabular}{cl}
\hline \multicolumn{2}{c}{ table of decision values } \\
\hline 1 & very very bad \\
\hline 2 & very bad \\
\hline 3 & bad \\
\hline 4 & enaught \\
\hline 5 & well \\
\hline 6 & very well \\
\hline 7 & very very good \\
\hline
\end{tabular}

From the results of the input obtained so that the value of the amount of each decision of the SmartPhone Brand Product can be determined, the results can be said as the basic table used for processing in the TOPSIS method, where the magnitude obtained from the eigenvector value is indicated as the weight of the criteria. Note (Table 2) the following are illustrated seven main criteria, 
namely: Performance, Feature, Design, Camera, Battery, and Memory. The determination of the eigenvector value can be obtained in two ways, namely: first it can be done with the Expert Choice Application and the second can be done using the Algebra Matrices method. In applying Algebra Matrices, it requires several iteration stages so that it does not produce the difference between the last eigenvector value and the previous eigenvector value that has passed several iterations. The results obtained from the Expert Choice Application can be seen in (Figure 1) which is the result obtained from a number of respondents which is used as input for the search process stage of the eigenvector value and (Figure 2) describes the process results obtained with the Expert Choice Application and used as a preference for reprocessing with the TOPSIS method in determining the normalization weight of the six criteria used as a measurement of the Smartphone Brand Product.

$\left[\begin{array}{llllll}1.0000 & 1.4010 & 1.8769 & 1.4515 & 1.4097 & 1.3502 \\ 0.7138 & 1.0000 & 1.4515 & 1.6128 & 1.6254 & 1.1444 \\ 0.5328 & 0.6899 & 1.0000 & 1.1999 & 1.7975 & 1.6955 \\ 0.6890 & 0.6201 & 0.8334 & 1.0000 & 1.1878 & 1.3892 \\ 0.7094 & 0.6153 & 0.5563 & 0.8419 & 1.0000 & 1.4946 \\ 0.7406 & 0.8738 & 0.5898 & 0.7198 & 0.6691 & 1.0000\end{array}\right]$

Figure 4. Preliminary Data on Algebra Matrices

$\left[\begin{array}{llllll}6.0000 & 7.0422 & 8.5777 & 9.5732 & 11.0978 & 11.6094 \\ 5.3126 & 6.0000 & 7.1661 & 8.1953 & 9.5474 & 10.3834 \\ 4.9148 & 5.4558 & 6.0000 & 7.0178 & 8.0255 & 9.2523 \\ 4.1360 & 4.7243 & 5.3402 & 6.0000 & 6.7823 & 7.6057 \\ 3.8413 & 4.4356 & 4.9203 & 5.4490 & 6.0000 & 6.7639 \\ 3.3998 & 4.0496 & 4.8102 & 5.1949 & 5.7177 & 6.0000\end{array}\right]$

Figure 5. Multiplication of Algebra Matrices

The algebra matrices process (Figure 5) has five iterations until it is found that there is no difference in value between the last eigenvector and the previous eigenvector, while the final results obtained by algebra matrices are noticed (Figure 6).

\begin{tabular}{cc} 
Eigenvector & Eigenvector Difference \\
\hline 0.227 & 0.000000000000000000000000000000 \\
\hline 0.196 & 0.00000000000000000000000000000 \\
\hline 0.172 & 0.000000000000000000000000000000 \\
\hline 0.147 & 0.000000000000000000000000000000 \\
\hline 0.134 & 0.00000000000000000000000000000 \\
\hline 0.124 & 0.0000000000000000000000000000000 \\
\hline
\end{tabular}

Figure 6. Eigenvector value without difference
The eigenvector value displayed in (Figure 6) explains that, the value of the eigenvector value without gives the difference meaning that the eigenvector is final and has great strength, if a sensitivity test is done, even vice versa if the eigenvector value is obtained by a different method with the iteration way method, it can be said that the decision taken has a slack if tested with a sensitivity test. Sensitivity tests can be done by changing the values according to the parameter limits ranging from 0.1 to 0.9 ; if there is a change, the decision is said to be weak, but conversely if the results of the sensitivity test do not experience changes in value, this means that the decision has extraordinary power, meaning that the decision determined describes a very mature consideration. The value obtained from the calculation process using the AHP method can be used as a preference for reprocessing with the TOPSIS method in determining normalization weight, note the weighting criteria shown in (Table 2) which will be processed using the TOPSIS method in determining the priority of decisions for SmartPhone Brand Products. .

Table 2. Decision Value

\begin{tabular}{lcccccc} 
Weight Criteria & 0.227 & 0.196 & 0.172 & 0.147 & 0.134 & 0.124 \\
\hline Criteria & Performance & Feature & Design & Camera & Battery & Memory \\
\hline Advance & 0.107 & 0.077 & 0.086 & 0.054 & 0.062 & 0.059 \\
\hline Xiaomi & 0.092 & 0.090 & 0.062 & 0.076 & 0.062 & 0.059 \\
\hline OPPO & 0.107 & 0.090 & 0.086 & 0.054 & 0.062 & 0.050 \\
\hline SAMSUNG & 0.107 & 0.090 & 0.074 & 0.065 & 0.062 & 0.050 \\
\hline VIVO & 0.092 & 0.090 & 0.074 & 0.076 & 0.053 & 0.059 \\
\hline
\end{tabular}

Referring to (Table 2) it can be seen that each weight has been given a point as a weight criterion, whose total magnitude is one hundred percent. With utilization (Table 2) the results of normalization will then be obtained. These results can be obtained using (equation-1) with results that can be seen in (Table 3) below.

Table 3. Normalization

\begin{tabular}{lcccccc}
\hline Citteria & Performance & Feature & Design & Camera & Battery & Memory \\
\hline Advance & 0.473 & 0.394 & 0.501 & 0.369 & 0.460 & 0.473 \\
\hline Xisomi & 0.405 & 0.450 & 0.358 & 0.516 & 0.450 & 0.473 \\
\hline OPPO & 0.473 & 0.450 & 0.501 & 0.369 & 0.460 & 0.405 \\
\hline SAMSUNG & 0.473 & 0.450 & 0.430 & 0.42 & 0.460 & 0.405 \\
\hline VIVO & 0.445 & 0.450 & 0.430 & 0.516 & 0.394 & 0.473 \\
\hline
\end{tabular}

To determine each weight of each criterion, we need a weight value from the eigenvector value obtained from the AHP method. The magnitude of each of the criteria and alternatives can determine the magnitude of each alternative based on the criteria used, so that it can determine the determination of the maximum value and the 
minimum value of each criterion in each alternative. The maximum value and minimum value can be used as an appropriate scale to determine the points of each alternative, so the value of the decisions taken has a very significant impact on the final decision that is optimal. Therefore, the positive ideal value and negative ideal value as a benchmark determine the best decision on a SmartPhone Brand Product.

Table 4. Weighted Normalization

\begin{tabular}{lcccccc}
\hline Criteria & Performance & Feazure & Design & Camera & Battery & Memory \\
\hline Adrance & 0.107 & 0.077 & 0.086 & 0.054 & 0.062 & 0.059 \\
\hline Xizomi & 0.092 & 0.090 & 0.062 & 0.076 & 0.062 & 0.059 \\
\hline OPPO & 0.107 & 0.090 & 0.086 & 0.054 & 0.062 & 0.050 \\
\hline SANSUNG & 0.107 & 0.099 & 0.074 & 0.065 & 0.062 & 0.050 \\
\hline VWV & 0.092 & 0.090 & 0.074 & 0.076 & 0.053 & 0.059 \\
\hline
\end{tabular}

By observing (Table 4) each criterion can influence a number of alternatives in determining the $\mathrm{V}$ dimension that is derived by an ideal positive solution symbolized by $\mathrm{D}+$ and a negative ideal solution. Symbolized by D-. Look again at the value of each criterion which seems to be seen which is the biggest and which is the smallest, so that is the right placement of alternatives in determining the ideal solution. The equation that can be used is (equation 3 ) and (equation 4).

Table 5. Ideal Positive Solutions

\begin{tabular}{lllllll}
\hline D1+ & 0.00000000 & 0.0001656 & 0.00000000 & 0.0004698 & 0.00000000 & 0.00000000 \\
\hline $02+$ & 0.0002353 & 0.0000000 & 0.0006069 & 0.00000000 & 0.00000000 & 0.00000000 \\
\hline $03+$ & 0.0000000 & 0.00000000 & 0.00000000 & 0.0004698 & 0.00000000 & 0.00000702 \\
\hline$D 4+$ & 0.0000000 & 0.0000000 & 0.0001517 & 0.0001174 & 0.00000000 & 0.00000702 \\
\hline $05+$ & 0.0000000 & 0.0001656 & 0.0001517 & 0.0004698 & 0.00000000 & 0.00000000 \\
\hline
\end{tabular}

Positive ideal solutions are taken from the determination of the largest value in each criterion which is then processed from the value of $n$ on a particular line divided by the reduction in the largest value and the value of the squared value. Each value of $\mathrm{n}$ on a particular line must be done in the same way to determine the location of the row value of the magnitude of the value in the specified range.

Table 6. Ideal Negative Solutions

\begin{tabular}{ccccccc}
\hline D1. & 0.0002353 & 0.0000000 & 0.0006069 & 0.00000000 & 0.0000774 & 0.00000702 \\
\hline D2. & 0.0000000 & 0.0001656 & 0.0000000 & 0.0004598 & 0.0000774 & 0.0000702 \\
\hline D3. & 0.0002353 & 0.0001656 & 0.0006069 & 0.0000000 & 0.0000774 & 0.0000000 \\
\hline D4. & 0.0002353 & 0.0001656 & 0.0001517 & 0.0001174 & 0.00000774 & 0.00000000 \\
\hline D5. & 0.0000000 & 0.0001656 & 0.0001517 & 0.0004698 & 0.0000000 & 0.00000702 \\
\hline
\end{tabular}

Taking into account (table 5) as a positive ideal solution and (table 6) as a negative ideal solution the two tables can be used to determine the dimension of $\mathrm{V}$ as a ranking benchmark, so that decision making can be done carefully. The table results of research on SmartPhone Brand Product can be resolved properly. The results of the SmartPhone Brand Product selection rank can be seen in (table 7) below.

Table 7. TOPSIS Ranking.

\begin{tabular}{cclc}
\hline Vx & Bobot V & Alternative & Ranking \\
\hline V1 & 0.555 & Advance & 3 \\
\hline V2 & 0.491 & Xiaomi & 5 \\
\hline V3 & 0.586 & OPPO & 2 \\
\hline V4 & 0.597 & SAMSUNG & 1 \\
\hline V5 & 0.511 & VIVO & 4 \\
\hline
\end{tabular}

\section{Conclusion}

Selection of SmartPhone Brand Product using the combination method between Analytic Hierarchy Process (AHP) and TOPSIS, provides optimal results in the ranking obtained, namely: The first rank is occupied by SAMSUNG with a weight of 0.597 , followed by the second ranking by OPPO with a weight of 0.586 , the third ranked continuation is occupied by an Advance with a weight value of 0.555 , and ranked fourth and fifth in sequence are VIVO with a weight of 0.551 and Xiaomi with a weight value of 0.491. Of the five SmartPhone BrandPproduct that greatly outperformed from SAMSUNG and this is an optimal decision that can be used as a reference in determining priorities. It is evident clearly that the Analytic Hierarchy Process (AHP) can be collaborated with TOPSIS, because both in one process determine the rank of each object evaluated.

\section{ACKNOWLEDGMENT}

The author would like to say thank you especially to children and wives who have helped and accompanied a lot in terms of thought and time to the author, and also to friend of author who are always ready to participate in science and no less important to Sinkron Journal who have helped in terms of publication and acceptance you for all.

\section{REFERENCES}

[1] A. Erbasi and R. Parlakkaya, "The use of Analytic Hieararchy Process inthe balanced scorecard: an approach in a Hotel Firm," Bus. Manag. Rev., vol. 2(2), no. 2, pp. 2337, 2012.

[2] Thomas L. Saaty, "How to make a decision: The Analytic Hierarchy Process," European Journal of Operational Research, vol. 48. 
pp. 9-26, 1990.

[3] Akmaludin, "Teknik Penyeleksian Keputusan Menggunakan Analytic Hierarchy Process," J. Pilar Nusa Mandiri, vol. 11, no. 2, pp. 102-111, 2015.

[4] Akmaludin, "Multicriteria Analysis Menentukan Point Weight Comparison Dalam Penetapan Decision Priority," $J$. Pilar Nusa Mandiri, vol. 11, no. 1, pp. 1119, 2015.

[5] A. Akmaludin and M. Badrul, "Comparison Ranking Aplikasi Animasi Berbasis Pembelajaran dengan Metode Promethee," J. Bina Insa., vol. 5, no. 1, pp. 1-10, 2018.

[6] A. Ishizaka and A. Labib, "Review of the main developments in the analytic hierarchy process," Pre Print Vertion, vol. 38, no. 11, pp. 14336-14345, 2011.

[7] a. K. Taslicali and S. Ercan, "The analytic hierarchy \& the analytic network processes in multicriteria decision making: A comparative study," J. Aeronaut. Sp. Technol., vol. 2, no. 4, pp. 55-65, 2006.

[8] S. Aouadni, A. Rebai, and Z. Turskis, "The
Meaningful Mixed Data TOPSIS (TOPSISMMD) Method and its application in supplier selection," Stud. Informatics Control, vol. 26, no. 3, pp. 353-363, 2017.

[9] K. Savitha and C. Chandrasekar, "Trusted Network Selection using SAW and TOPSIS Algorithms for Heterogeneous Wireless Networks," Int. J. Comput. Appl., vol. 26, no. 8, pp. 22-29, 2011.

[10] S. Opricovic and G. H. Tzeng, "Compromise solution by MCDM methods: A comparative analysis of VIKOR and TOPSIS," Eur. J. Oper. Res., vol. 156, no. 2, pp. 445-455, 2004.

[11] V. S Nmamit, S. Aithal, and S. G, "Integrating TOPSIS and AHP into GORE Decision Support System," Int. J. Comput. Appl., vol. 56, no. 17, pp. 46-53, 2012.

[12] A. Ishizaka and A. Labib, "Analytic Hierarchy Process and Expert Choice: Benefits and limitations," OR Insight, vol. 22, no. 4, pp. 201-220, 2009. 